\title{
Experimental Study on Polymer Nanocomposites Based Strain Sensors for Structural Health Monitoring
}

\author{
R. Kiran ${ }^{1}$, K. R. Prakash ${ }^{2}$, Poorna Chandra ${ }^{1}$ (), V. Ravi Kumar ${ }^{1}$, P. B. Asha ${ }^{1}$, C. R. Prakash Rao ${ }^{1}$ \\ ${ }^{1}$ Department of Mechanical Engineering, Global Academy of Technology, Bengaluru, India \\ ${ }^{2}$ Department of Mechanical Engineering, NIE, Mysuru, India \\ Email: kiranr9387@gmail.com
}

How to cite this paper: Kiran, R., Prakash, K.R., Chandra, P., Kumar, V.R., Asha, P.B. and Rao, C.R.P. (2021) Experimental Study on Polymer Nanocomposites Based Strain Sensors for Structural Health Monitoring. Journal of Minerals and Materials Characterization and Engineering, 9, 512-527.

https://doi.org/10.4236/jmmce.2021.95034

Received: July 27, 2021

Accepted: September 14, 2021

Published: September 17, 2021

Copyright $\odot 2021$ by author(s) and Scientific Research Publishing Inc. This work is licensed under the Creative Commons Attribution International License (CC BY 4.0).

http://creativecommons.org/licenses/by/4.0/

\section{(c) (i) Open Access}

\begin{abstract}
The aim is to develop a mechanically flexible polymer nanocomposite film-based strain sensors that could act towards sustainable structural health monitoring for civil structures. The developed polymer nanocomposite film combinations will be monitored for their structural, electrical and mechanical behaviors and the optimized formulations will be tried for strain sensing applications. The films were cast by using PVA as the base polymer and copper doped silver nitrate as the nanofiller along with the use of glycine as fuel which is a combination of silver and copper nitrate. After preparing the films, they were tested for conductivity under tensile loading using a digital multi meter connected to a UTM. The samples were subjected to XRD, FTIR and SEM for further analysis. The results of the experiments shown I-V characteristics of PVA$\mathrm{CuAgO}$ composites from $5 \%$ to $25 \% \mathrm{CuAgO}$ have been increased tremendously with the incorporation of filler material. For $100 \mathrm{~V}$, the maximum current value obtained for plain PVA is only 7.7E-8 A, whereas $\mathrm{CuAgO}$ particles shown $0.0025 \mathrm{~A}$ at $5 \%$ reinforcements and further increased nearly to $0.025 \mathrm{~A}$ for $25 \%$ of $\mathrm{CuAgO}$ particles into the PVA matrix.
\end{abstract}

\section{Keywords \\ Polymer, Nanocomposites}

\section{Introduction}

Nanotechnology helps us to understand the concept of matter in the range of nanoscale. The major application of Nanoparticles is in electronic engineering and medical electronics. Polymer nanomaterial has very wide applications due to 
its properties such as surface area, high aspect ratio and good mechanical properties. These properties provide, great opportunities in the field of material science. Also, these properties can be tailored so that they can provide better mechanical properties using the nanoparticles. The copper doped silver nanoparticles can be used as filler with PVA as the matrix which shows prominent improvement in the mechanical properties such as tensile strength, Elastic modulus, flexural strength and stiffness.

\section{Literature Review}

The literatures pertaining to fabrication of Polymer nanocomposites showed that the nanocomposites can be fabricated with great difficulty and the expected properties may be achieved by combining polymer matrix with many non-ferrous nanoparticles. Zare et al. [1] carried out research work on biomedical application of polymer/metal nanocomposites. The authors observed that application areas such as sensing devices, health and medicines are the highly potential areas. Nunes-Pereira et al. [2] carried experiments on poly vinylidene fluoride composites filled with carbon nanotubes, during their research the authors found the suitability and ability of tailoring the properties of the polymer nanocomposites for specific applications. Wolf et al. [3] carried out research work on strain sensor applications of plasma deposited conductive polymer composites. The authors used different sizes of copper nanoparticles for their experiments. The authors analyzed the resistance characteristics of the CPC films during elongation of the nanocomposites; the copper nanoparticles shown change of resistance of $20 \%$ for $3.33 \%$ elongation of copper/polyisoprene composites. Arfat et al. [4] carried out research work on preparation and characterization of agar based nanocomposites reinforced with silver-copper nanoparticles. The authors results of the research work shown that the agar based nanocomposites reinforced with silver-copper nanoparticles are eco-friendly, since can be used for the food packaging applications. Dai et al. [5] developed a carbon nanotube based non-woven composed sensors which can be used to determine strain sensing properties for structural health monitoring application. The strain sensor is developed by applying carbon nanotube to a non-woven fabric that creates a conductive network. These sensors are able to exhibit a strain gauge factor of 1.9 and 4.0 in the longitudinal and transverse directions. Loomis et al. [6] conducted the study on stimuli response of carbon nanotube to determine the physical properties, mechanical properties, and the electrical resistance transformations in single direction. The nanocomposites are fabricated using polydimethylsiloxane and carbon nanotubes and acrylic microspheres as fillers and these composites exhibited the transformations in properties such as macroscopic volume, expansion above $500 \%$, decrease in the density more than $80 \%$ and expansion of elastic modules greater than $675 \%$.

Singh [7] carried out the research work on carbon nanotubes based nanocomposites and synthesized CNT's and PMMA nanocomposites for EMA [EWA] 
and dynamic strains sensing for the monitoring of structures. These CNT's were characterized using XRD and SEM. The CNT's/PMMA nanocomposites showed the metallic properties during its investigation. CNT's/PMMA nanocomposites exhibited static as well as dynamic response through the vibration pattern as same as that of the standard strain sensors. It also exhibited the piezo resistance effect as that of a strain sensor. It also showed good flexibility and electrical conductivity which enables it to function as a strain sensor for structural health monitoring in aerospace applications. Catalán [8] carried out the study on composite materials and synthesized polydimethylsiloxane and polyisoprene based graphene composites which can be used for sensing strain in the applications of health monitoring. Also these composites do function as opto-electro mechanical sensors. Here two types of composite materials were developed where polyisoprene and polydimethylsiloxane were used as a matrix, and graphene, molybdenum sulfide were used as the filler materials and these materials were characterized in order to measure the current and voltage behavior to evaluate the strain sensing ability of the composite. With the addition of graphene the resistance increases with the increase in strain. Takei [9] carried out a study on nanocomposites and developed a highly sensitive e-whiskers carbon nanotube and silver nanoparticles composites films which are able to exhibit high strain sensitivity. The carbon nanotubes show high bendability, and it forms a conductive network. Also, with the addition of nanoparticles the conductivity of the composites increases, and it is possible to synthesize the composites with excellent strain sensitivity. The resistivity of the composites is a function of strain up to 8\% per Pascal for the whiskers which is 10 times greater than the earlier capacitive sensors. Zhang [10] conducted a study on strain sensors which can be used in electronic skin applications. Here nanocomposites were synthesized by varying Ag concentrations and these materials possess high sensitivity to temperature and strain. These materials were characterized mechanically, and the samples exhibited highest gauge factor of 137.6 in the linear region between $0 \%$ 17.3\% with Ag-CNTs1 and the sensor with Ag-CNTs2 exhibited a gauge factor of 14.9 and the result suggested that the above materials can be used as e-skin sensors.

Melnykowycz [11] carried out a study on monofilament polymer sensors. These sensors have the potential applications in clothing, gloves, and robotics. A highly stretchable monofilament sensor is fabricated from carbon black with thermo plastic elastomer [PPE] and it possesses good flexural characteristics than the commercially available silicon rubber monofilament. Robert et al. [12] developed the sensing skin of $1.5 \mu \mathrm{m}$ thickness which consists of 40 nanolayers of conductive polymer composites [CPC]. These skins were synthesized by depositing the material layer by layer on a PET woven material. Various factors such as the thickness and initial resistance can be adjusted to monitor the response pertaining to sensitivity and stability of the samples. The polymer matrix such as PC- $1 \% \mathrm{CNT}$ was considered as the best materials catering the chemical and physical condi- 
tions.

The strain sensor is used in structural health monitoring due to its excellent properties. Dai et al. [13] developed a novel CNT based strain sensor for structural health monitoring. They fabricated aramid nonwoven carrier fabric using CNT and Epoxy resin and it exhibited an elastic gauge factor of 1.90 and nonlinear gauge factor of 5.34 respectively.

The Polyester resin can also be used as the matrix material owing to its superior mechanical properties. Liu et al. [14] prepared graphene reinforced tung oil (TO)-based unsaturated polyester nanocomposites using in situ melt polycondensation integrated with Diels-Alder addition. Functionalized graphene sheets were extracted from the nanocomposite and then it is characterized. The graphene nanosheets were dispersed in the composites. Also attempts were made to determine the ultimate properties of the nanocomposites. The Graphene oxide was added to the Tung oil based polyester resin and the mechanical \& thermal properties were found to be increased. By using the bio based unsaturated polyester resins the tensile strength and modulus and Glass transition temperature increased considerably and hence the developed bio based UPR nanocomposites are very promising to be applied in structural plastics

Zhang et al. [15] carried out research work on Mechanical reinforcement of unsaturated polyester resin using $\mathrm{Al}_{2} \mathrm{O}_{3}$ nanoparticles. They fabricated polymer nanocomposites reinforcing Alumina particulates using unsaturated polyester resin as matrix material. The specimens were subjected to a 3 point bending test following ASTM standards. They observed poor bonding of reinforcement with the unsaturated polyester matrix resulting in lack of crack trapping which leads to lower fracture toughness. However, by attaining proper reinforcement bonding they attained higher fracture toughness.

Evora et al. [16] carried out research work on fabrication characterization \& dynamic behavior of polyester/ $/ \mathrm{TiO}_{2}$ nanocomposites. Here direct ultrasonification method was used to fabricate the unsaturated polyester resin specimens reinforced with $\mathrm{TiO}_{2}$ particles. The Transmission electron microscopy was employed to observe the particle dispersion. The fracture toughness was increased owing to the presence of the $\mathrm{TiO}_{2}$ particles. The Scanning electron microscopy was carried out to observe the toughening mechanism. The increase in dynamic fracture toughness was observed during the dynamic fracture toughness testing. When the specimens were subjected to high strain rate testing, a slight stiffening effect was observed.

Sadeghian et al. [17] carried out research work on manufacturing carbon nanofibers toughened polyester/glass fibre composites using Resin transfer molding process to enhance the Mode-I delamination resistance. Here Vacuum assisted resin transfer molding was used to impregnate the glass fiber perform into the CNF resin suspension. The presence of CNF concentration, resin viscosity and the micro void formation was examined. There is a considerable improvement in the Glass transition temperature with the addition of $1 \%$ wt. CNF into the polyester resin. The fracture surface of the toughened polyester/Glass fibres 
composite samples was more complex than the fracture surfaces of the regular polyester/glass fibre composites.

Le et al. [18] carried out the research work on thermal and mechanical behavior of hybrid polymer nanocomposite reinforced with graphene nanoplatelets and fabricated a polymer nanocomposite containing Epoxy/polyester blends and graphene nanoplatelets. A high speed mechanical stirrer is used to mix the above mixture with hardener. The samples were made using hot press casting method. The specimens were subjected to Tensile tests, Dynamic mechanical analysis and thermo gravimetric analysis to determine the effect of reinforcement on the mixture. The tensile tests suggest that the tensile modulus of the specimen increases with the addition of graphene oxide. Also, the DMA results indicate that GNP-reinforced epoxy/polyester nanocomposite consists of highest storage modulus and glass transition temperature when compared to neat epoxy/polyester blend. The TGA results indicates that it possess higher thermal stability.

Lu et al. [19] carried out research work on unsaturated polyester resins/Graphite nanosheets conducting composites and fabricated the composites with a low percolation threshold of $0.64 \mathrm{vol} \%$ using insitu polymerization. Mean field theory and excluded volume theory are used to represent the low volume fraction. The composites prepared exhibited a better graphite nanosheets conductive network due to the low percolation threshold and also there exists contact resistance in the percolating network. Also, SEM micrograph reveals that the conductivity can be monitored by contact resistance in the percolating system. The Thermo gravimetric analysis reveals that the thermal stability of unsaturated polyester re$\sin /$ Graphite nanosheets is weakened due to the degree of cross linking.

Kausar [20] has done review on fundamentals of polyester nanocomposites filled with carbonaceous fillers. The polyester is a well-known matrix material which possesses good bio-degradability and superior thermal, mechanical and chemical properties. The nanofillers can be used as reinforcement with synthetic aromatic polyester resins to achieve better structural and physical properties. Here the nanofillers such as Nanodiamond, Fullerene, CNT, graphene and graphene oxide were used. The improved interaction between the matrix and the nanofiller, the functionality of fillers and the better design of polyesters helps in obtaining the superior properties in the polyester nanocomposites. The developed Polyester/nanocomposites are used in various fields such as Supercapacitors, Fuel cells, shape memory materials, Electromagnetic shielding materials, textiles and Bio-medical appliances.

\section{Preparation of Nanocomposite}

\subsection{Synthesis of Ag-Cu Bimetallic Nanoparticle Preparation}

The Poly Vinyl Pyrolidone (PVP) mediated Ag-Cu bimetallic nanoparticles were synthesized via microwave irradiated green chemical synthesis route. In a typical synthesis, stoichiometric amounts, viz., $20 \times 10^{-3} \mathrm{M}$ copper nitrate and $20 \times 10^{-3}$ $\mathrm{M}$ silver nitrate were dissolved in ethylene glycol in a molar ratio of 1:1. To this 
solution was added $0.5 \mathrm{~g} / \mathrm{ml}$ of PVP dissolved in $10 \mathrm{ml}$ ethylene glycol as capping agent. The resultant solution was then pre-heated to $1500^{\circ} \mathrm{C}$ for $20 \mathrm{~min}$, and microwave irradiated with an operating frequency of $2000 \mathrm{MHz}$ for $2 \mathrm{~min}$. This microwave irradiation turned the initially blue colored solution into near light brownish yellow colored solutions which were then subjected to sudden quenching in an ice bath. The resulting suspensions were then centrifuged at $6000 \mathrm{RPM}$ for $10 \mathrm{~min}$ to obtain the desired $\mathrm{AgCu}$ bimetallic nanoparticles.

\subsection{Preparation of Nanocomposite}

$250 \mathrm{ml}$ of water is subjected to boiling, once the water attains the desired temperature, add $6 \mathrm{wt} \%$ of Poly Vinyl Alcohol (PVA) which is having a molecular weight of 40,000 to 50,000. Continue it with constant magnetic stirring of nearly 400 to $450 \mathrm{rpm}$ and constant heating until the added Polyvinyl Alcohol is completely dissolved and forms a homogeneous solution. Prepare the nanocomposite $\mathrm{AgCuO}$ and keep it under room temperature for 24 hours. Then prepare composite solutions containing $0 \%, 5 \%, 10 \%, 15 \%$ and $25 \%$ fillers and make it to $50 \mathrm{ml}$ by prepared Poly Vinyl Alcohol and thus the solution is ready. Stir the Composites gently and then pour it into the mold, take maximum care during pouring such that no bubble formation and external contamination takes place. Keep composite solutions containing $0 \%, 5 \%, 10 \%, 15 \%$ and $25 \%$ fillers for drying to about 48 hours under room temperature. Thus PVA-AgCuO films with varied filler content were ready to conduct the experimentation. Figure 1 shows the films of different compositions used for the research work.

\section{Experimental Methodology}

\subsection{Test for Potential}

The prepared samples were tested for conductivity using a multi meter in order to check the conductivity of the prepared samples with varied concentrations. The readings shown on the multi meter display was recorded.

Figure 2 shows the electrical resistance test of the sample having $15 \%$ nanoparticle. The conductivity of the nanocomposite depends on following
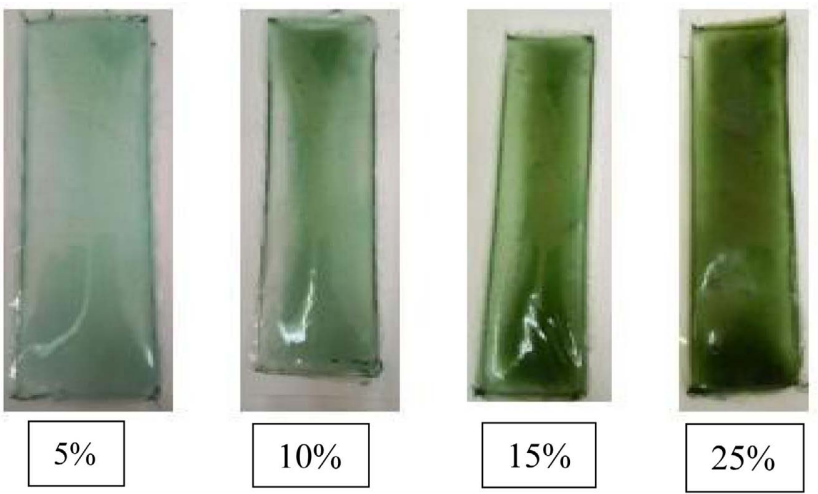

Figure 1. Films of different compositions used for the research work. 


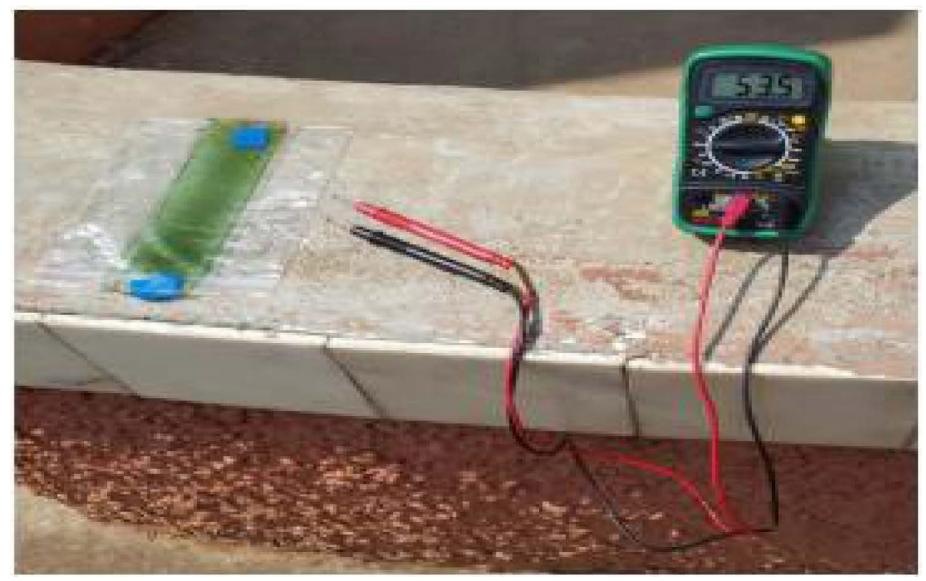

Figure 2. Samples tested for electrical resistance.

factors such as, amount of filler content, amount of PVA content, distance between the probes and temperature.

\subsection{Test for Evaluation of Conductivity under Tensile Load}

The test was conducted in the Universal Testing Machine (UTM). Under tensile loading the samples of varied filler content were subjected to tensile test and the influence of the tensile load on the conductivity was measured during tensile test and Figure 3 shows the test set up.

\subsection{Specification and Make of XRD, SEM, EDAX}

The specifications and instrument details of Bench top X-Ray Diffractometer (XRD) with advanced detector is tabulated in Table 1. The details of the Scanning Electron Microscope used for the experiments are tabulated in Table 2.

\section{Study of XRD, SEM, EDAX \& FTIR}

\subsection{XRD Analysis}

X-Ray Diffraction (XRD) identifies crystalline materials which is having crystal domains greater than $3-5 \mathrm{~nm}$. Each peak in a diffractogram results from a corresponding d-spacing. As it can be seen from Figure 4, all the films under investigation shows peak at scattering angles $\left(19^{\circ}<28^{\circ}<20^{\circ}\right)$ and the d-spacing value or the distance between the planes of atoms found to be $4.38 \AA$ corresponding to (101) crystal plane of semi crystalline PVA.

The presented $\mathrm{AgCuO}$ nanofiller composite films show further diffraction peaks at $2 \theta$ values of $101,110,111,11-1$ and $200^{\circ}$ confirming the occurrence of inorganic nanofillers in the organic mass. The shift in the peak of $0 \% \mathrm{CuAgO}$ samples may be owing to crystallinity and the area considered for the analysis.

\subsection{SEM Analysis}

The PVA matrix and PVA-AgCuO nanocomposite samples were subjected to SEM analysis to check the electron interaction with atoms in the sample and also 


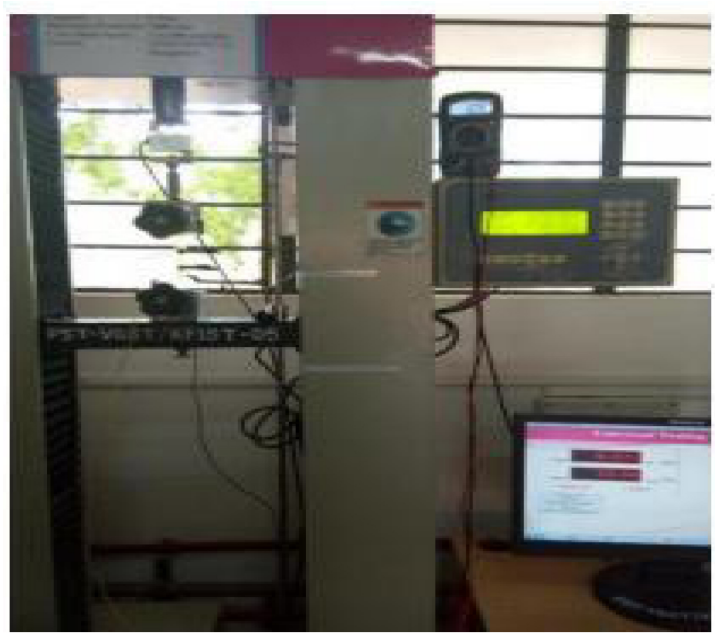

Figure 3. Setup for tensile and conductivity testing.

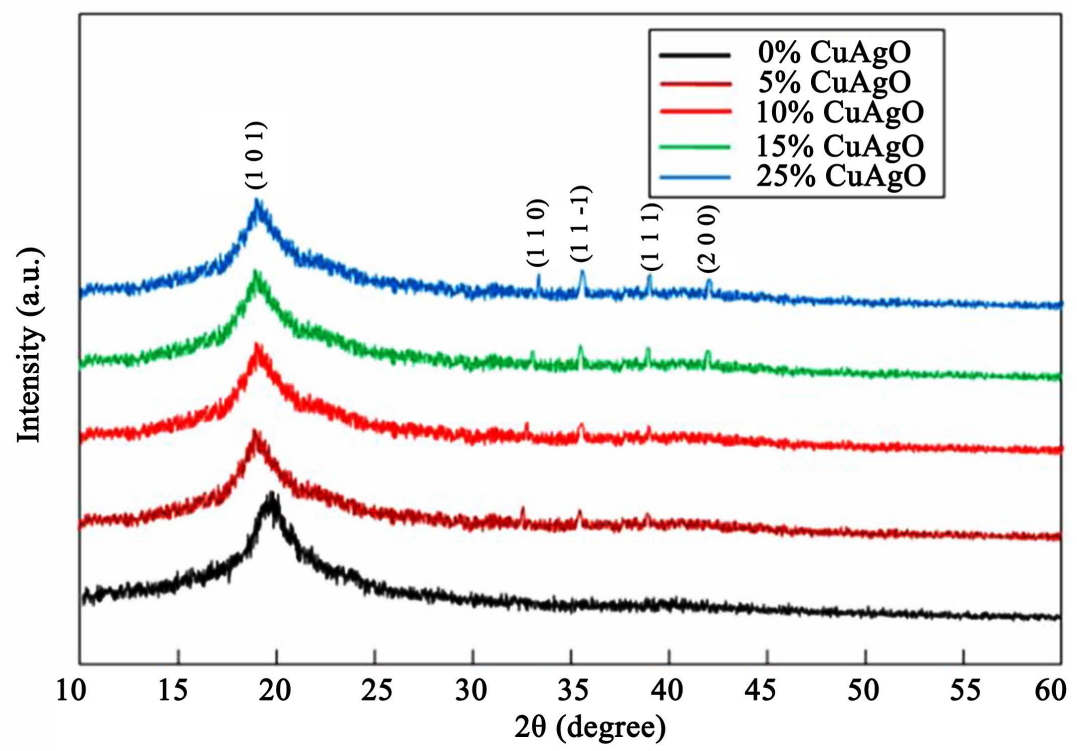

Figure 4. XRD patterns for PVA/AgCuO Nanocomposite films.

Table 1. Specification of XRD advanced detector.

\begin{tabular}{|c|c|}
\hline Product name & Mini Flex \\
\hline Technique & X-Ray Diffraction (XRD) \\
\hline Benefit & Phase analysis of poly-crystalline materials \\
\hline Technology & Benchtop X-ray diffractometer with advanced detector \\
\hline Core attributes & $\begin{array}{l}600 \mathrm{~W} \text { X-ray tube, D/teX Ultra silicon strip detector, } \\
\text { accepts unusual samples, tabletop form factor }\end{array}$ \\
\hline Core options & $\begin{array}{l}\text { 8-position autosampler, HyPix-400 MF ( } 2 \mathrm{D} \text { HPAD) detector, graphite } \\
\text { monochromator, air sensitive sample holder, Shape Flex sample holder }\end{array}$ \\
\hline Core dimensions & $620(\mathrm{~W}) \times 722(\mathrm{H}) \times 460(\mathrm{D}) \mathrm{mm}$ \\
\hline Mass & $80 \mathrm{~kg}$ (core unit) \\
\hline Power requirements & $1 \varnothing, 100-240 \mathrm{~V} 50 / 60 \mathrm{~Hz}$ \\
\hline
\end{tabular}


Table 2. Specification of scanning electron microscope.

\begin{tabular}{cc}
\hline Resolution & HV mode: $3.0 \mathrm{~nm}, \mathrm{LV}$ mode: $4.0 \mathrm{~nm}$ \\
Magnification & $\times 5-\times 300,000$ \\
Accelerating voltage & $0.3 \mathrm{kV}$ to $30 \mathrm{kV}$ \\
Specimen stage & 5 -axis motor stage \\
Maximum sample diameter & $\mathrm{X}: 125 \mathrm{~mm} \mathrm{Y:} 100 \mathrm{~mm}$ Z: 5 to $80 \mathrm{~mm}$ T: -10 to $90^{\circ}$ R: $360^{\circ}$ \\
Options & $200 \mathrm{~mm} \varphi$ \\
\hline
\end{tabular}

to know the samples topography and composition. The results of the analysis shows that the presence of the filler materials in the nanocomposite materials. The SEM image of the PVA matrix is shown in Figure 5 and the image of the PVA-AgCuO nanocomposite material containing 15\% filler is shown in Figure 6.

\subsection{FTIR Analysis}

The FTIR (Fourier Transform Infrared Spectra) for pure PVA and PVA/metal nanocomposite of different concentration of $5 \%, 10 \%, 15 \%$ of $\mathrm{AgCuO}$ is as shown in Figure 7. The PVA obtained as a hydrolytic derivative of polyvinyl acetate (PVAc) shows IR characteristic peaks of both -OH groups and residual acetate groups of unhydrolyzed PVAc. The peak around $1767-1680 \mathrm{~cm}^{-1}$ is due to the residual acetate groups of partially hydrolyzed PVAc. The O-H enlarging vibrations of PVA support of IR spectrum of PVA and nanocomposite shows a wide and strong band around $3500-3095 \mathrm{~cm}^{-1}$. The electrostatic relation between - $\mathrm{OH}$ group and $\mathrm{AgCuO}$ nanoparticles is due to peak of -OH group of PVA is moved in PVA/AgCuO nanocomposite sample to lower wave number. The absorption band occurred around $2973-2886 \mathrm{~cm}^{-1}$ resembles to asymmetric broadening mode of $-\mathrm{CH}_{2}$ group and the peak at $1525-1478 \mathrm{~cm}^{-1}$ corresponds to $\mathrm{C}-\mathrm{H}$ bending of $-\mathrm{CH}_{2}$ group in the PVA support. A band at $1276-1258$ $\mathrm{cm}^{-1}$ corresponds to wagging of $-\mathrm{CH}_{2}$ group. The presence of more absorbance band at $565-525 \mathrm{~cm}^{-1}$ in the IR spectra of PVA/AgCuO nanocomposite films may be recognized to metal-oxygen stretching, which in turn justifies the presence of $\mathrm{AgCuO}$ in PVA matrix as tabulated in Table 3.

\section{Energy dispersive X-ray fluorescence (EDAX)}

The Energy dispersive X-ray fluorescence is carried out to PVA matrix and newly developed nanocomposite material containing varied percentage of the $\mathrm{AgCuO}$ filler, the EDAX image of the PVA matrix is shown in Figure 8 and the image of the nanocomposite is shown in Figure 9.

\section{Result and Discussion}

\subsection{Test for Evaluation of Conductivity under Tensile Load}

The readings of load versus displacement and influence of tensile load on the 


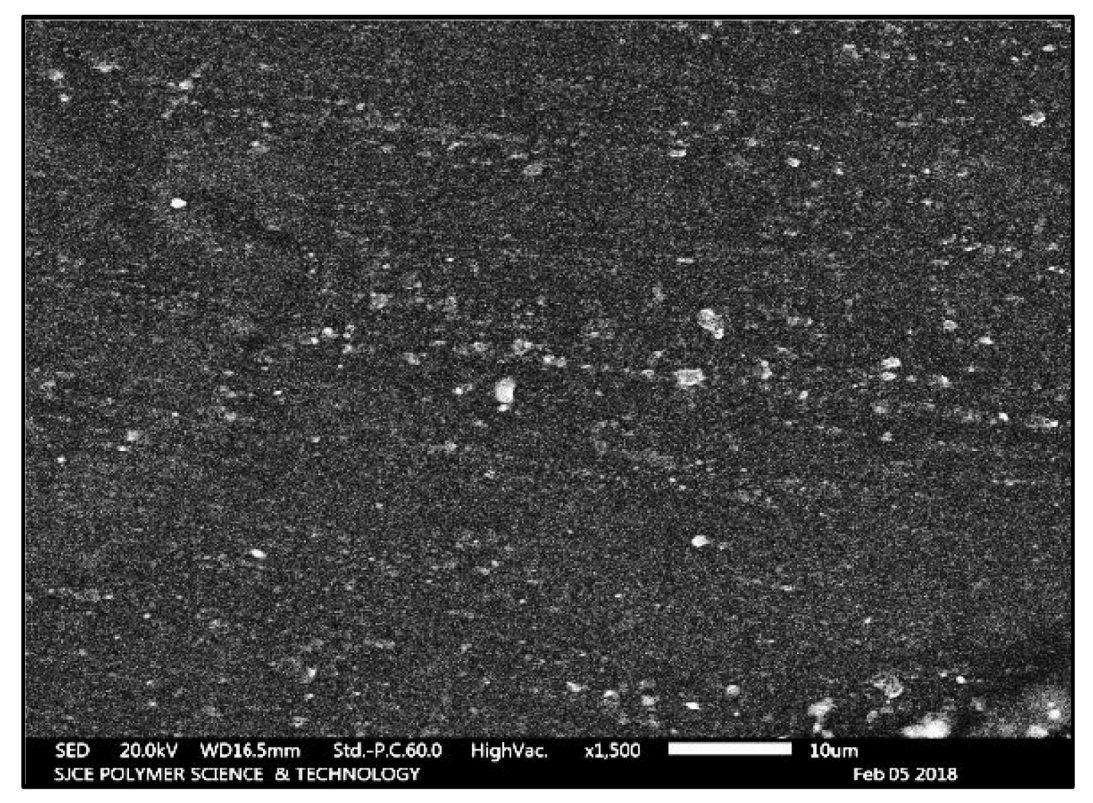

Figure 5. SEM analysis image of PVA.

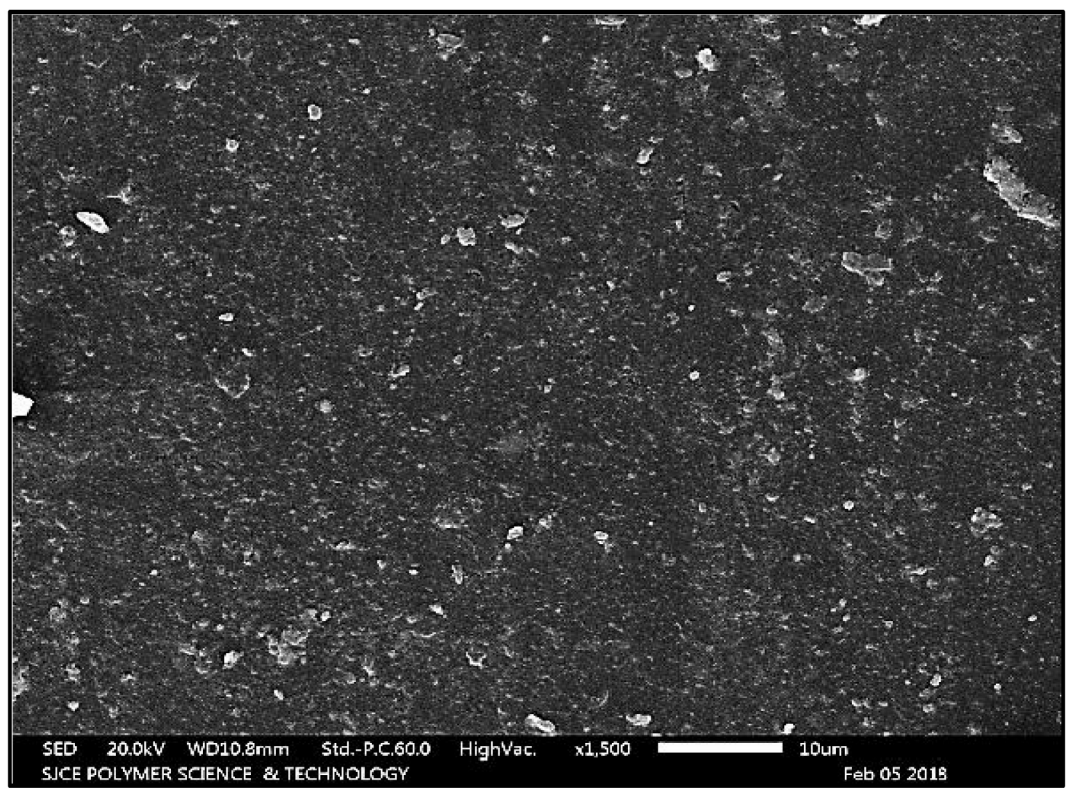

Figure 6. SEM analysis image of PVA-AgCuO Nanocomposite.

Table 3. Characteristic vibrational spectral band of PVA/AgCuO nanocomposite film.

\begin{tabular}{cc}
\hline Wave number $\left(\mathrm{cm}^{-1}\right)$ & Assigned vibrational spectral band \\
\hline $3500-3095$ & $\mathrm{O}-\mathrm{H}$ stretching \\
$2973-2886$ & $\mathrm{C}-\mathrm{H}$ stretching \\
$1767-1680$ & $(\mathrm{C}=\mathrm{O})$ stretching \\
$1525-1478$ & $\mathrm{CH}_{2}$ bending \\
$1276-1258$ & $\mathrm{CH}_{2}$ wagging \\
$565-525$ & Metal-oxygen stretching
\end{tabular}



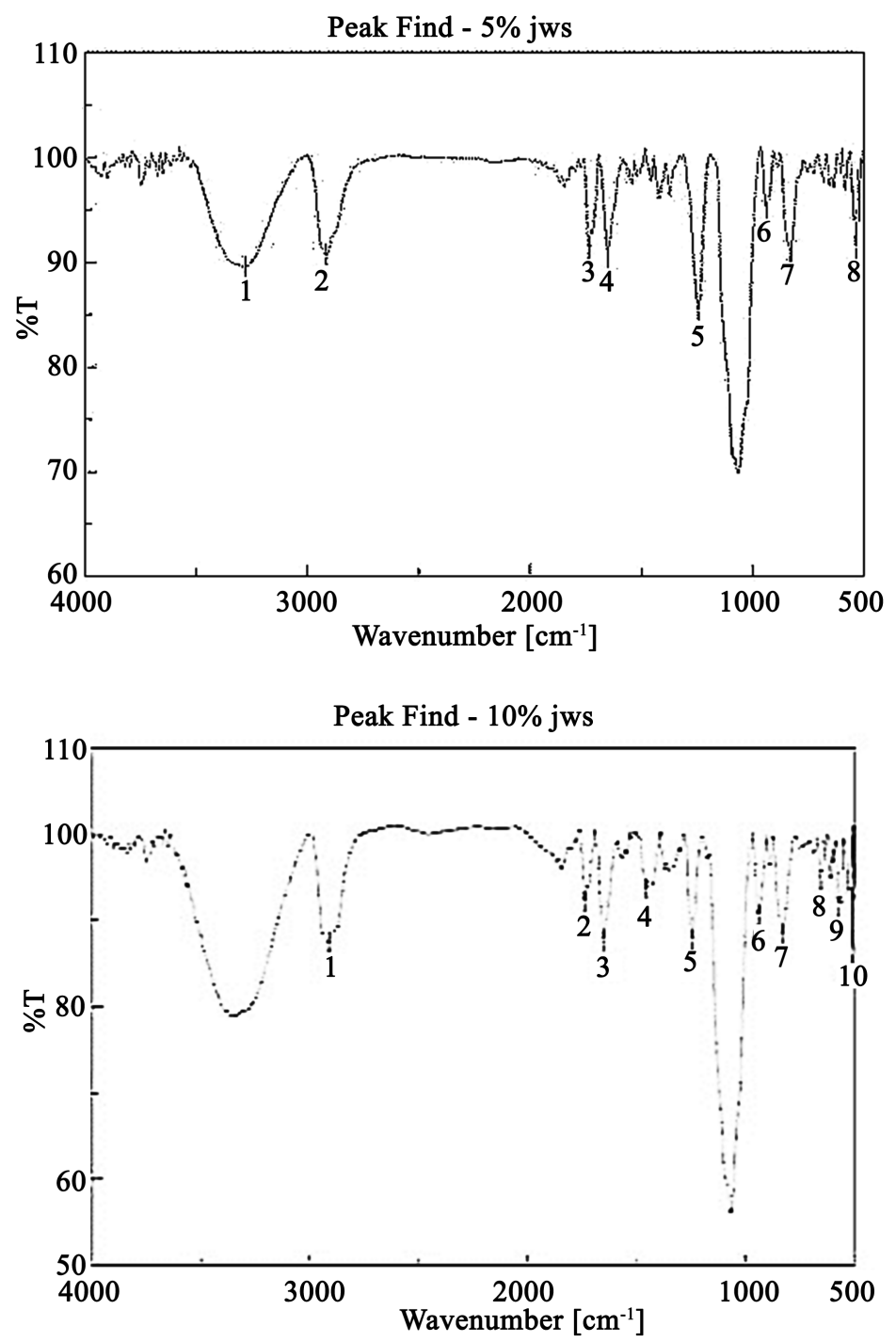

Peak Find - $15 \%$ jws

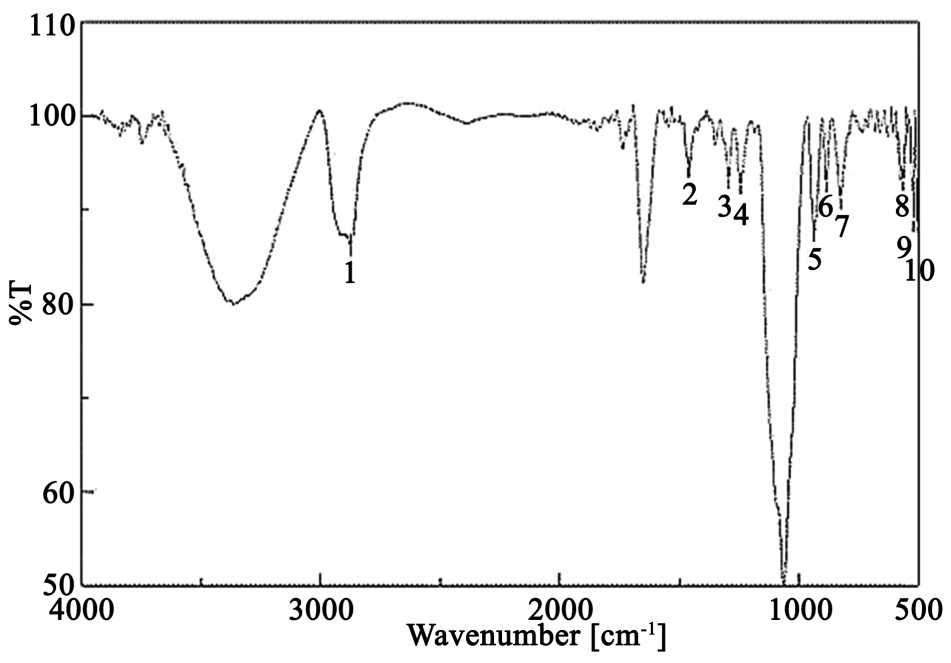

Figure 7. Represents the FTIR graphs of different Nanofiller concentration (5\%, 10\%, $15 \%)$ respectively. 


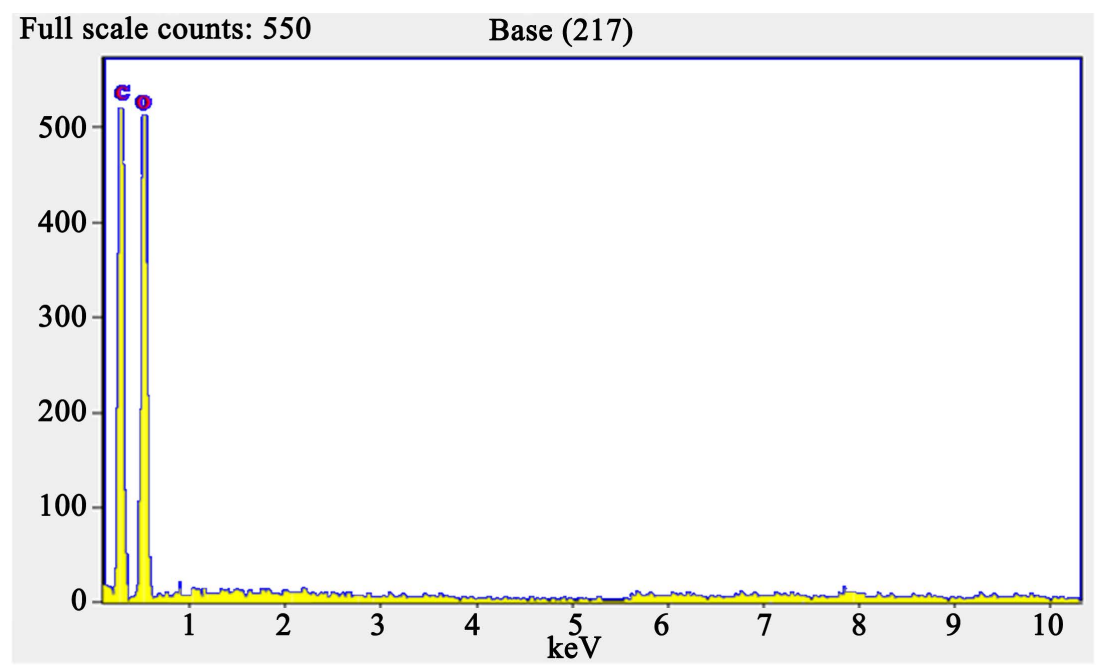

Figure 8. EDAX image of PVA matrix.

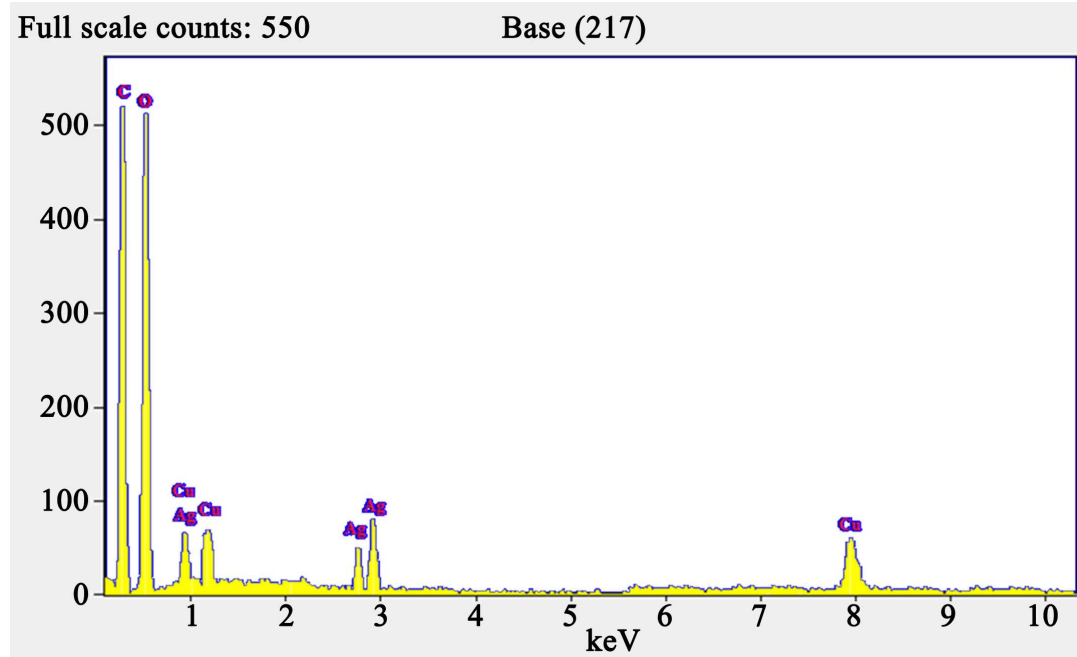

Figure 9. EDAX image of PVA-AgCuO reinforced nanocomposite.

conductivity were recorded for varied filler concentrations of nanofiller polymer films. Both the tensile load reading and the resistance reading were collected simultaneously.

Table 4 shows the resistance in ohms versus tensile loading of different compositions and the same is shown in Figure 10. The resistance versus tensile loading test was not carried out for the $0 \%$ filler since PVA is an insulating material, hence, only tensile test was conducted.

\subsection{I-V Measurement}

The effect of percent reinforcement on the current-voltage characteristics was studied for the PVA-CuAgO composites. Based on the current-voltage characteristics obtained for PVA-CuAgO composites, two graphs have been plotted separately for Plain PVA and varied filler percent, that is $5 \%$ to $25 \%$ in steps of $5 \%$ (Figure 11, Figure 12, Table 5). 
Influence of tensile load on conductivity

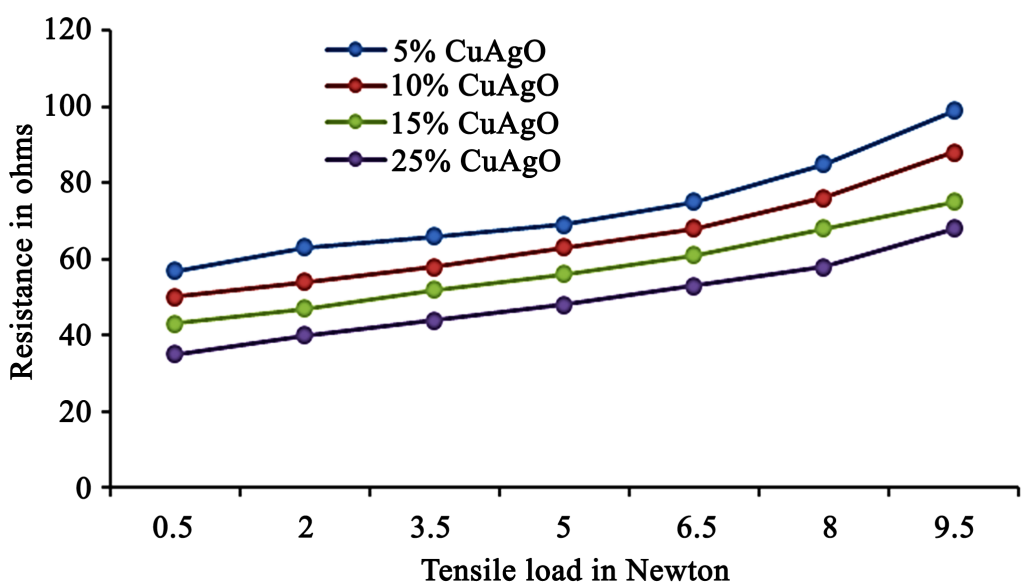

Figure 10. Resistance versus load of $\mathrm{CuAgO}$.

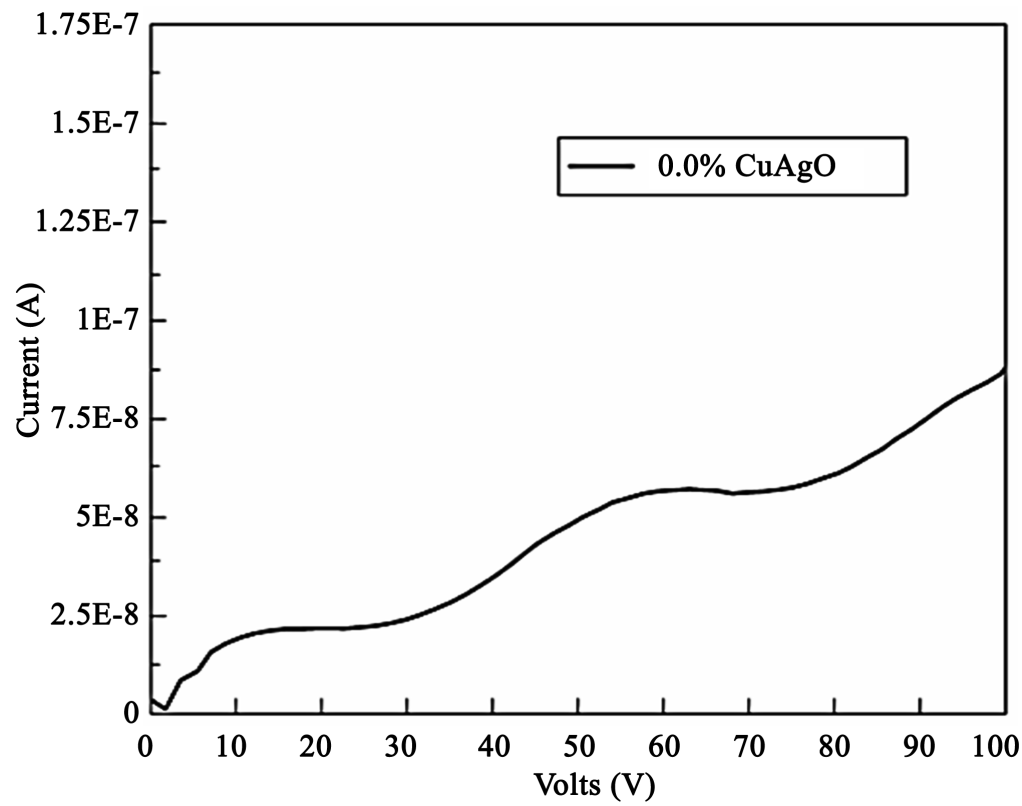

Figure 11. I-V Characteristics of plain PVA.

Table 4. Resistance in ohms versus load in $\mathrm{N}$ of $\mathrm{CuAgO}$.

\begin{tabular}{ccccc}
\hline \multicolumn{5}{c}{ Nanocomposite materials } \\
\hline Load in N & $5 \%$ CuAgO & $10 \%$ CuAgO & $15 \%$ CuAgO & $25 \%$ CuAgO \\
\hline $0.5 \mathrm{~N}$ & 57 & 50 & 43 & 35 \\
$2 \mathrm{~N}$ & 63 & 54 & 47 & 40 \\
$3.5 \mathrm{~N}$ & 66 & 58 & 52 & 44 \\
$5 \mathrm{~N}$ & 69 & 63 & 56 & 48 \\
$6.5 \mathrm{~N}$ & 75 & 68 & 61 & 53 \\
$8.0 \mathrm{~N}$ & 85 & 76 & 68 & 58 \\
$9.5 \mathrm{~N}$ & 99 & 88 & 75 & 68
\end{tabular}




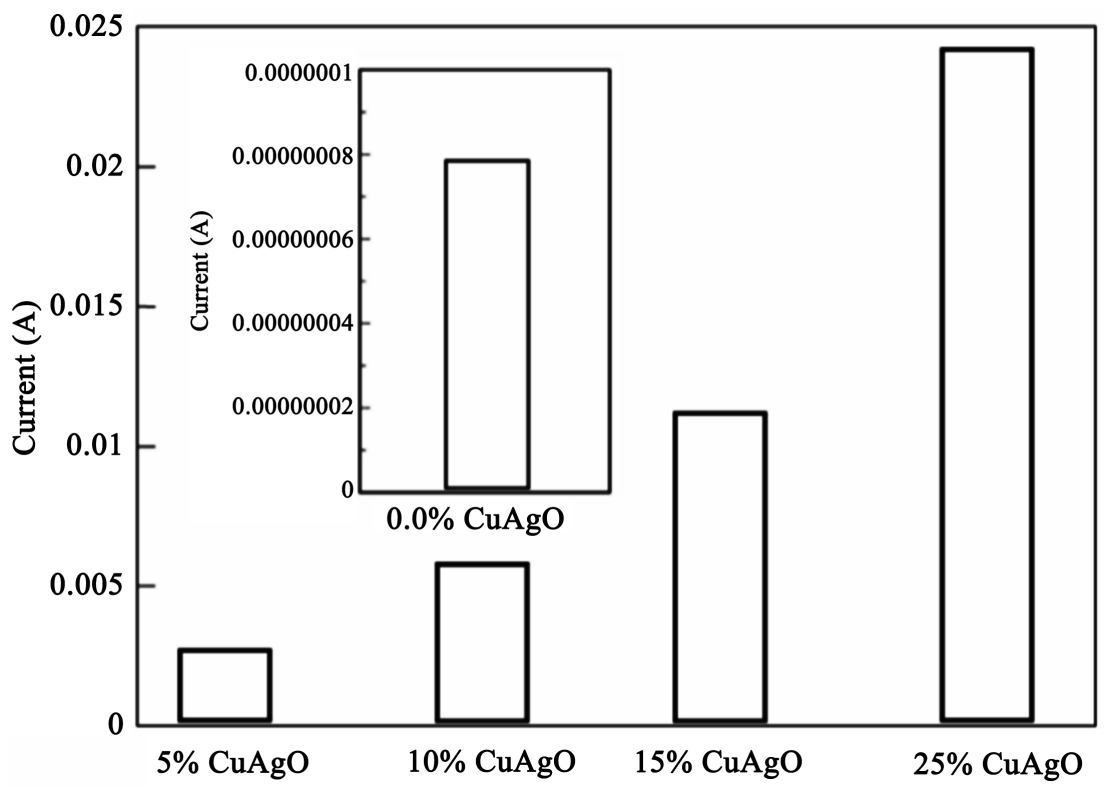

Figure 12. Conductivity of PVA-CuAgO 2 Composites for 0 - $4 \mathrm{wt} \% \mathrm{CuAgO}_{2}$ loading at $100 \mathrm{~V}$ potential.

Effect of percent filler \& voltage on current

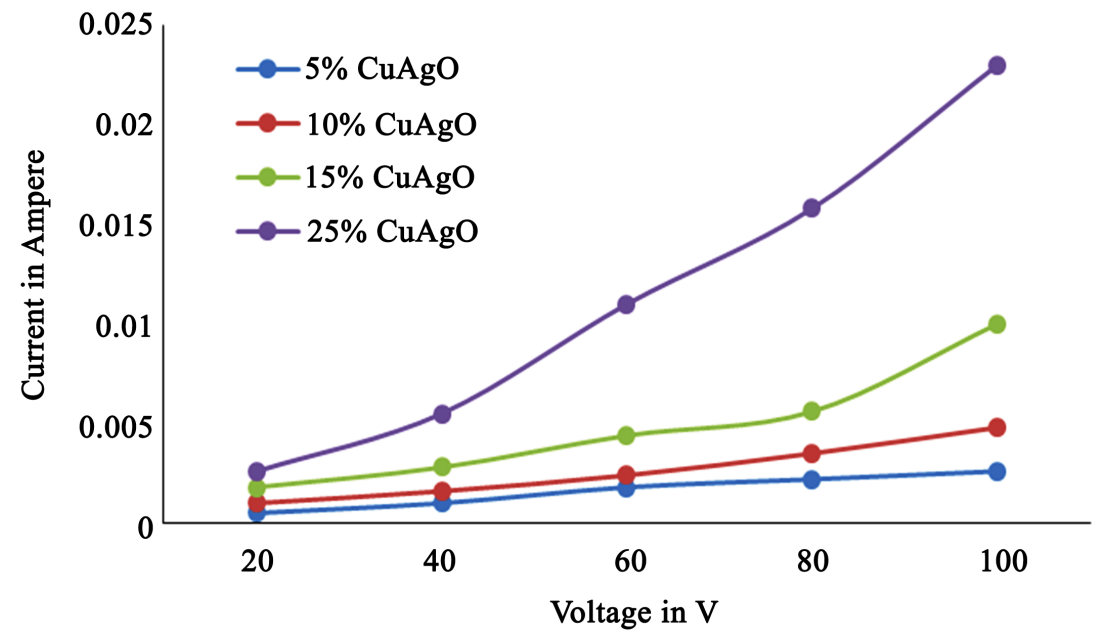

Figure 13. Conductivity of PVA-CuAgO ${ }_{2}$ Composites for 0 - $4 \mathrm{wt} \% \mathrm{CuAgO}_{2}$ loading at $100 \mathrm{~V}$ potential.

Table 5. Effect of percent filler \& voltage on current in Ampere.

\begin{tabular}{ccccc}
\hline \multicolumn{5}{c}{ PVA-CuAgO composite materials } \\
\hline Volts & $5 \% \mathrm{CuAgO}$ & $10 \% \mathrm{CuAgO}$ & $15 \% \mathrm{CuAgO}$ & $25 \% \mathrm{CuAgO}$ \\
\hline 20 & 0.0005 & 0.0010 & 0.0018 & 0.0026 \\
40 & 0.0010 & 0.0016 & 0.0028 & 0.0055 \\
60 & 0.0018 & 0.0024 & 0.0044 & 0.0110 \\
80 & 0.0022 & 0.0035 & 0.0056 & 0.0158 \\
100 & 0.0026 & 0.0048 & 0.0100 & 0.0230
\end{tabular}


Results of the experiments shown that I-V values have been increased tremendously with the addition of the filler material. For 100 volts, maximum current value obtained for plain PVA is only 7.7E-8 Amp. When 5\% CuAgO particles was reinforced has yielded around $0.0025 \mathrm{Amp}$, and the same is shown in Figure 13. It has been further increased nearly to $0.025 \mathrm{Amp}$ for $25 \%$ of $\mathrm{CuAgO}$ particles reinforced into the PVA matrix.

\section{Conclusion}

Newly developed $\mathrm{CuAgO}$ particles reinforced into the PVA matrix nanocomposite thin films were mechanically flexible which can be used for the purpose of structural health monitoring in civil structures such as bridges, buildings and strain sensing applications. The nanocomposite thin films were fabricated by introducing conductive nanofiller into the insulating PVA matrix, we achieved desired conductivity. In civil structures the materials will be subjected to a high load so the material needs to possess conductivity even under constant high load conditions, so we performed a test for conductivity under tensile loading in a UTM machine. It was observed that with an increase in the amount of filler content, the resistivity decreased and thus conductivity increases.

\section{Conflicts of Interest}

The authors declare no conflicts of interest regarding the publication of this paper.

\section{References}

[1] Zare, Y. and Shabani, I. (2016) Polymer/Metal Nanocomposites for Biomedical Applications. Materials Science and Engineering: C, 60, 195-203. https://doi.org/10.1016/j.msec.2015.11.023

[2] Nunes-Pereira, J., et al. (2018) Poly(vinylidene fluoride) Composites with Carbon Nanotubes Decorated with Metal Nanoparticles. Composites Part B: Engineering, 142, 1-8. https://doi.org/10.1016/j.compositesb.2017.12.047

[3] Wolf, M., et al. (2009) Plasma Deposition of Conductive Polymer Composites for Strain Sensor Applications. Procedia Chemistry, 1, 879-882. https://doi.org/10.1016/j.proche.2009.07.219

[4] Arfat, Y.A., Ahmed, J. and Jacob, H. (2017) Preparation and Characterization of AgarBased Nanocomposite Films Reinforced with Bimetallic (Ag-Cu) Alloy Nanoparticles. Carbohydrate Polymers, 155, 382-390. https://doi.org/10.1016/j.carbpol.2016.08.097

[5] Dai, H., Thostenson, E.T. and Schumacher, T. (2015) Processing and Characterization of a Novel Distributed Strain Sensor Using Carbon Nanotube-Based Nonwoven Composites. Sensors, 15, 17728-17747. https://doi.org/10.3390/s150717728

[6] Loomis, J., Xu, P. and Panchapakesan, B. (2013) Stimuli-Responsive Transformation in Carbon Nanotube/Expanding Microsphere-Polymer Composites. Nanotechnology, 24, Article ID: 185703. https://doi.org/10.1088/0957-4484/24/18/185703

[7] Singh, A.K. (2013) Carbon Nanotubes Based Nanocomposite for Electromagnetic Wave Absorption and Dynamic Structural Strain Sensing. 
[8] Catalán, J.A. and Kaul, A.B. (2017) Polydimethylsiloxane and Polyisoprene-Based Graphene Composites for Strain-Sensing. Journal of Vacuum Science \& Technology B, Nanotechnology and Microelectronics. Materials, Processing, Measurement, and Phenomena, 35, 03D106. https://doi.org/10.1116/1.4979603

[9] Takei, K., et al. (2014) Highly Sensitive Electronic Whiskers Based on Patterned Carbon Nanotube and Silver Nanoparticle Composite Films. Proceedings of the National Academy of Sciences, 111, 1703-1707.

https://doi.org/10.1073/pnas.1317920111

[10] Zhang, Q., et al. (2017) Highly Sensitive and Stretchable Strain Sensor Based on Ag@ CNTs. Nanomaterials, 7, 424. https://doi.org/10.3390/nano7120424

[11] Melnykowycz, M., et al. (2014) Comparison of Piezoresistive Monofilament Polymer Sensors. Sensors, 14, 1278-1294. https://doi.org/10.3390/s140101278

[12] Robert, C., Feller, J.F. and Castro, M. (2012) Sensing Skin for Strain Monitoring Made of PC-CNT Conductive Polymer Nanocomposite Sprayed Layer by Layer. ACS Applied Materials \& Interfaces, 4, 3508-3516. https://doi.org/10.1021/am300594t

[13] Dai, H.B., Thostenson, E.T. and Schumacher, T. (2015) Processing and Characterization of a Novel Distributed Strain Sensor Using Carbon Nanotube-Based Nonwoven Composites. Sensors, 15, 17728-17747. https://doi.org/10.3390/s150717728

[14] Liu, C.G., et al. (2018) High-Performance Biobased Unsaturated Polyester Nanocomposites with Very Low Loadings of Graphene. Polymers, 10, 1288. https://doi.org/10.3390/polym10111288

[15] Zhang, M. and Singh, R.P. (2004) Mechanical Reinforcement of Unsaturated Polyester by $\mathrm{Al}_{2} \mathrm{O}_{3}$ Nanoparticles. Materials Letters, 58, 408-412. https://doi.org/10.1016/S0167-577X(03)00512-3

[16] Evora, V.M.F. and Shukla, A. (2003) Fabrication, Characterization, and Dynamic Behavior of Polyester/TiO ${ }_{2}$ Nanocomposites. Materials Science and Engineering. $A$, 361, 358-366. https://doi.org/10.1016/S0921-5093(03)00536-7

[17] Sadeghian, R., et al. (2006) Manufacturing Carbon Nanofibers Toughened Polyester/Glass Fiber Composites Using Vacuum Assisted Resin Transfer Molding for Enhancing the Mode-I Delamination Resistance. Composites Part A: Applied Science and Manufacturing, 37, 1787-1795.

https://doi.org/10.1016/j.compositesa.2005.09.010

[18] Le, M.-T. and Huang, S.-C. (2015) Thermal and Mechanical Behavior of Hybrid Polymer Nanocomposite Reinforced with Graphene Nanoplatelets. Materials, 8, 55265536. https://doi.org/10.3390/ma8085262

[19] Lu, W., et al. (2006) Unsaturated Polyester Resin/Graphite Nanosheet Conducting Composites with a Low Percolation Threshold. Polymer, 47, 4440-4444. https://doi.org/10.1016/j.polymer.2006.03.107

[20] Kausar, A. (2018) Review of Fundamentals and Applications of Polyester Nanocomposites Filled with Carbonaceous Nanofillers. Journal of Plastic Film \& Sheeting, 35, 22-44. https://doi.org/10.1177/8756087918783827 